\title{
Inadequate Lap Length Improvement in Precast Concrete Beams Connections
}

\author{
Mohammed Noori Hussein Alhashimi ${ }^{1}$

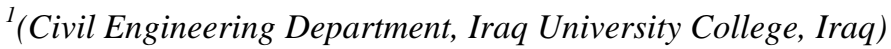

\begin{abstract}
The motivation behind this research is to provide a method to improve the beam to beam connection of precast concrete with inadequate lap length. The methodology of this research divided into two Parts. In the first Part, the paper tests six beam to beam connections. This was considered the preliminary findings of the study. Those beam to beam connections which derived optimum performance were proposed to be involved in the second Part. In the studies, plates made of steel, bolts and nuts system and technique of welding were used to enhance the performance of the anchorage system. The experiment on the welded end plate connection system indicates a good result as it increases the capability of bars for bearing and resisting the slippage between reinforcement and concrete significantly. The findings also show that there are many unsatisfactory connections. Nevertheless, they still have potentials for reaching the required loading capacity. Thus, as a way forward, more studies could improve their performance.
\end{abstract}

Keywords: Precast Concrete, Inadequate Lap Length, Beams connection.

\section{Introduction}

Reinforced concrete is consisting of concrete ingredient with steel bars which is called reinforcement combined together. The reinforced concrete can resist the compressive strength by the concrete itself and the tensile strength by the steel on the concrete structure. The defect of plain concrete that it is not able to resist tensile and shear stresses that are caused in some causes such as high speed wind, vibration, and earthquakes and other natural forces [1].

When a moderate load is applied to the reinforced concrete and the bond stress capacity is not exceeded, there will be a limited movement between the reinforced steel and the surrounding concrete. Nevertheless, for intensive loading conditions where the capacity of the localized bond demand greater than its capacity, several damage for the localized movement between reinforcing steel and the surrounding concrete will occur [2].

Previous empirical works showed that in the case of precast concrete structures, the elements of the structure are brought together to form the skeleton structure that are expected to distribute the loads on the foundations. Precast elements are usually fabricated in factory where the qualities of members are usually properly controlled. Therefore, connections become the most essential factor influencing the performance of the structures, as improper connections among structural members will lead to failure of structures. In order to ensure the loads are properly transfer among structural members, the bond strength between concrete and steels at joints should be greater than the forces to be transferred and the development of the bond strength is influenced by the development length of the anchorage of [3].

The arrangements for anchorage of reinforced bars and hooks sometimes providesitemizingissues because of the long development lengths and huge bend diameters that are needed, especially when hugediameter reinforcing bars are utilized. Sporadically those necessities for straight bar anchorage and lap spliced can't be given inside the accessible measurements of components. Hooked bars can be utilized to abbreviate anchorage length, but in many cases, the bend of the hook will not fit within the dimensions of members or the hooks make congestion and make element hard to construct. Mechanical anchorage devices can be used to shorten lap splice length, but they frequently require special construction operations and careful attention to tolerances [4]

This research studies about the tension anchorage length in precast beam-to-beam connections and the method to improve their performance. The study also intended to develop a new anchorage system, which is more effective in developing bond strength with minimum anchorage length. The study consists of five sections. First section provides the introduction and a review of the related studies. In the second section, the study presents the research methodology. Third section presents the result of the study. In the fourth section, the discussion is given. Lastly, the fifth section presents the conclusion of the study. 


\section{Materials and Methods}

Basically, the experiment consists of two Parts namely Part I and Part II. The primary objective of Part I is to find out a satisfactory anchorage system out of six proposed connection systems. It utilized the cross sectional tensile zone of beam specimens to study the tensile resistance and behavior. Steel plates, bolts and nuts system and welding techniques were used to enhance to performance of the anchorage system. Then the best anchorage system was selected to study the beam-to-beam connection performance in Part II.

Part II studies the development of cracks and loading behavior of beam-to-beam connection with different lapping lengths. The aims are to obtain an optimum anchorage length to be considered into practice in construction industry.

\section{Part I: beam with singlebar}

The essential target of this Part is to discover a palatable anchorage system, out of six proposed connection systems, that is able to provide comparable strength as conventional lapping system.

\subsection{Testing Procedure}

Damaging tests were led through incremental the applied forces gave by hydraulic jet keeping in mind the end ultimate loading capacities of the samples. The improvement of cracks and loading conduct were checked with a specific end goal to comprehend their execution under the applied forces.

\subsection{Design of Specimens}

Six $1.6 \mathrm{~m}$ long reinforced concrete beams were fabricated for testing six different anchorage systems. Similar cross sectional area of $200 \mathrm{~mm} \times 150 \mathrm{~mm}$ was used for all the specimens. Beam specimen with adequate and inadequate lapping length was prepared as Control Specimens $\mathrm{C} 1$ and $\mathrm{C} 2$ respectively.

\section{Part II: F-frame Beam-to-Beam Connection Test}

In Part II a beam-to-beam connection was chose as the best anchorage system for further comprehension about its execution. Cracks development and the behavior of loading of the beam-to-beam connection under incremental load were observed carefully. The lapping lengths in this part were varied in order to study the influence of the lapping length to its performance and to acquire an optimum lapping for the beamto-beam connection.

\subsection{Testing Method}

A test frame was used to conduct tests on the specimens in Part II. The precast column of F-frame was loaded axially at $95 \mathrm{KN}$ and was restrained at both ends to resist the rotation while loadings were applied. Then, incremental loads were applied on the precast column at $850 \mathrm{~mm}$ from the column face.

A total of three dial gauges were placed at $250 \mathrm{~mm}$ interval from the column face in order to record its rotation under incremental load. Three steel strain gauges, as well as two concrete strain gauges, were also setup to understand the strain condition of the reinforcement bars, steel plates and concrete surface. Then, as the incremental loads were applied, a data logger was used to record all the data, which include loadings, displacements and also gauge readings, to be analyzed.

\subsection{Design of Specimens}

Before conducting the experiment, a total of three precast concrete columns and beams were prepared separately before joining the components together by using the proposed beam-to-beam connection. Then the lapping length of the beam-to-beam connection varied from $50 \mathrm{~mm}$ to $250 \mathrm{~mm}$ with $100 \mathrm{~mm}$ interval (see Table 3.1). The dimension of precast concrete columns and beams were $200 \mathrm{~mm} \times 250 \mathrm{~mm} \times 2000 \mathrm{~mm}$ and $300 \mathrm{~mm} \times$ $180 \mathrm{~mm} \times 1200 \mathrm{~mm}$ respectively.

\subsection{Preparation of Specimens}

Generally, the preparation of specimens comprises of steel works and concrete works. In term of steel work, it is consisted of cutting, bending, welding and tying steel bars. Steel bar tensile test was also conducted to obtain the yielding stress of steel bars. On the other hand, the concrete works are involving the preparing formworks, casting, compacting and curing. For the purpose of obtaining the concrete strength of the specimens at certain duration after casting, $150 \mathrm{~mm} \times 150 \mathrm{~mm} \times 150 \mathrm{~mm}$ cubes were prepared for cube test.

\subsubsection{Steel works}

As main reinforcement, a high yield strength steel bars, Y16 and Y18, were used for specimen in Part I and Part II. There was no transverse reinforcement was provided in specimen for Part I. Meanwhile, mild steel R8 and R6 were used as shear links for precast concrete columns and beams in Part II. Steel works were 
conducted using equipment available in laboratory such as bar cutter, bar bender and others. In order to prepare shear links, a mould was prepared to bend the mild steel into its intended dimension and shape.

Reinforcement bars were vital for providing strength in reinforced concrete. Hence, it is recommended that they be tied together properly to ensure greatest quality of work.

\subsubsection{Concrete Works}

For this study concrete Grade 35 was used throughout the experiment. So as to guarantee great nature of concrete, ready mixed concrete was properly placed in timber formworks and was compared properly.

\section{Part I: Simple single-bar beam}

\section{Results}

Six beam specimens, with two control specimens, were tested in laboratory in Part I. The followings are the results and discussions of beam specimens in Part I.

The plots of loading versus deflection of all specimens are presented in Figure 1. In addition, a summary of performance of all the specimens are given in Table 1. Based on the findings, it can be seen that specimens give a satisfactory result compared to other proposed specimens. The horizontal steel plates provide no influencing contribution to the specimen. Therefore, anchorage system with end plate is chosen for further study of beam-to-beam connection in Part II.

Table 1 summarizes the performance of all proposed anchorage system in Part I. Specimen (S), connection type (CT), ultimate load (UL), moment (M), deflection (D), failure mode (FM) are presented in the table.

\section{Part II: Beam-to-Beam Connection}

Anchorage system C-W had showed great performance in Part I. Therefore, it was selected as beam-tobeam connection for further study in Part II. The followings are the results and discussions of F-frame specimens in Part II.

It can be seen that when the anchorage length is long, the loading capacity of the specimens is greater. For example, the specimen F1 shows the best outcome as it gave the closest result in terms of the ultimate loading to the monolithic structure. The ultimate limit state of Specimen F1 is $38 \mathrm{KN}$ as compared to $42 \mathrm{KN}$.

The result of Part II of the experiments is presented in Figure 2which shows the graph of load versus tension concrete strain of all the specimen of Part II. First cracks were always occurred at construction joint throughout the experiments in Part II. According to the load-strain graph, Specimen F1 performed better compared to other specimens, as higher load was required to reach similar strain. A slight fluctuation of the reading of Specimen F3 looked a bid odd. It may due to improper bonding between the strain gauge and the concrete surface that led to slight slippage of the strain gauge onto the concrete surface. However, it was observed that the resistance to the crack at the construction joint was less with smaller anchorage length.

The moment versus the rotation of the beam are given in Figure 3. It is found that for specimens F1 and F2, the beam-to-beam connections showed similar behavior as monolithic structure until $33 \mathrm{kNm}$. However, specimen F3 reached its loading capacity at a very early stage. Beyond ultimate load, the displacements of the beams developed at relatively higher rate compared to the columns. As a result, rapid development of connection rotation occurred with decreasing in moment capacity.

Judging on the moment-rotation curves of samples F1 and F3, the proposed (beam-to-beam connection can possibly give the solid loading limit. Be that as it may, it is hard to measure the obliged lapping to accomplish a flawless solid conduct because of the reason that construction joint is dependably the basic issue in cracking.

\section{Loading Capacity Versus Anchorage Length}

Figure 3 demonstrates that the addition of anchorage length has prompted the augmentation of loading capacity of the sample. The augmentation of lapping length from $100 \mathrm{~mm}$ to $300 \mathrm{~mm}$ has essentially expanded its loading capacity. Be that as it may, the level of impact of the load-anchorage length to the loading capacity lessened an offer from $100 \mathrm{~mm}$ to $200 \mathrm{~mm}$. From the load-anchorage length diagram, an ideal lapping length yet to be resolved as the chart is as yet rising. Accordingly, keeping in mind the end goal to turn out with an ideal lapping length, further study ought to be taken for more prominent safe anchorage lengths of beam-to-beam.

\section{Moment Capacity Versus Anchorage Length}

The increment of anchorage length of the beam-to-beam connection which shown in Figure 4 indicated that there is significant contribution to moment capacity of anchorage system. The moment capacity was contributed by the steel tensile force and slippage force between steel and concrete. As the lapping length increased the magnitude of moment capacity increase. The degree of influence of the anchorage length decreased at higher load level. Similarly, to the conclusion in section 4.6, the optimum lapping length is yet to be determined. Therefore, it is suggested that further study to be conducted to come out with an optimum lapping length. 


\section{Figures and Tables}

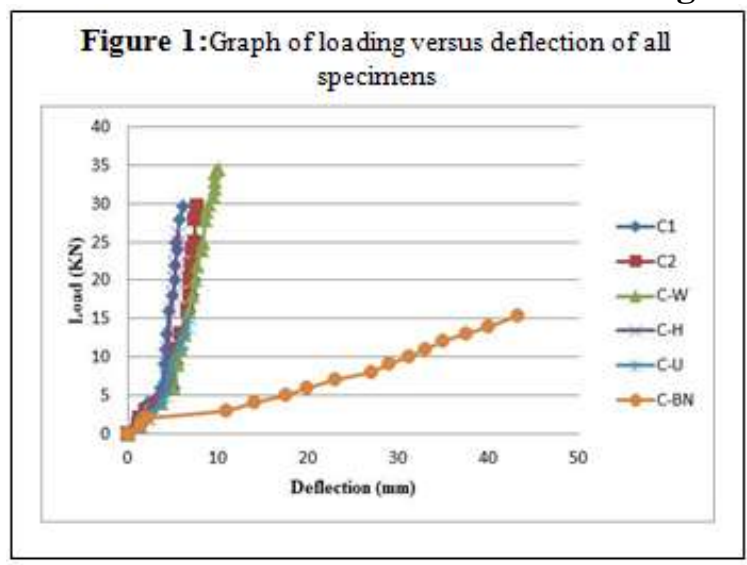

Figure 2: Graph loa ding versus tension concrete strain (construction joint) for all specimens

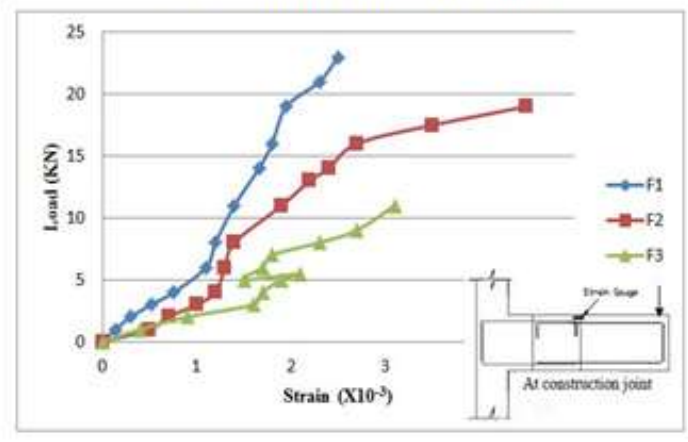

Figure 3: Graph moment versus rotation of beam

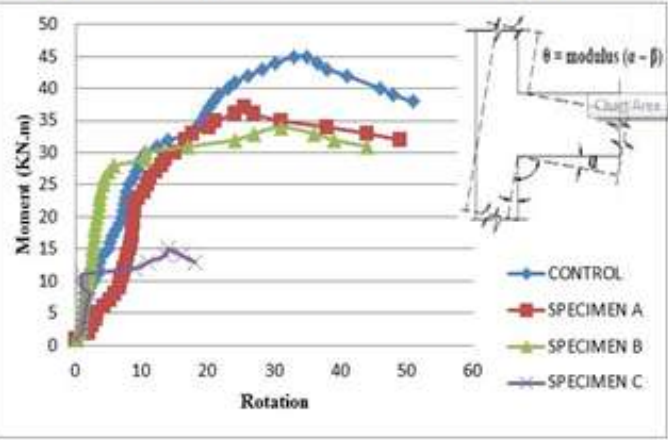

Figure 4:Loa ding capacity of specimen at different anchorage length

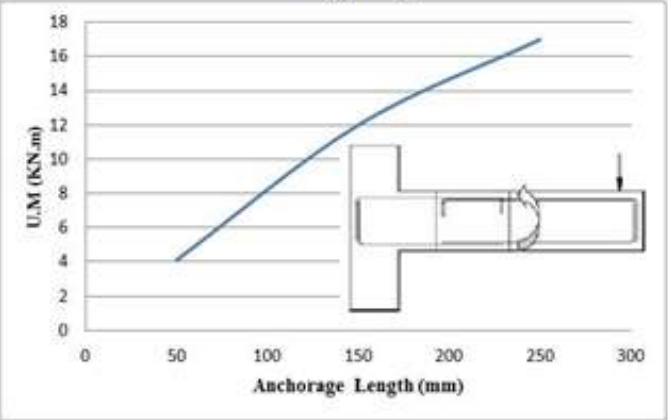

Figure 5:Moment capacity of beam-to-beam connection with different anchorage length

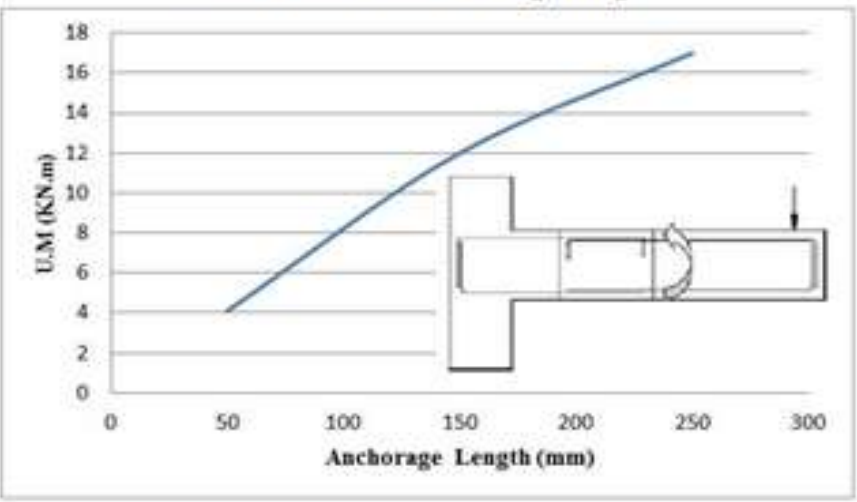

Table 1:Summary of Part I

\begin{tabular}{|l|l|l|l|l|}
\hline S & UL & M & D & FM \\
\hline C1 & 29.7 & 4.72 & 6.14 & failure at support (shear force) \\
\hline C2 & 29.7 & 4.72 & 7.7 & failure at mid span (Flexural) \\
\hline C-W & 34.5 & 5.79 & 10.1 & failure at support (shear force) \\
\hline C-H & 26 & 4.21 & 5.6 & failure at support (shear force) \\
\hline C-U & 18 & 3.13 & 7.1 & failure at mid span (Flexural) \\
\hline C-BN & 15.3 & 2.54 & 43.3 & cracks(large at mid-span and small at support) \\
\hline
\end{tabular}




\section{Discussion}

For the purpose of obtaining the optimum design of the welded steel end plate anchorage system and to obtain more reliable evidence of its feasibility, there is need for further studies. However, based on the findings of the present study, many recommendations are emerged. The followings are recommendations for future studies of the welded steel end plates anchorage system.

First, there is need to conduct more studies on the influence of anchorage length to the loading behavior of F-frame at longer lapping length, for example $400 \mathrm{~mm}, 500 \mathrm{~mm}$ and $550 \mathrm{~mm}$ lapping length, in order to acquire an optimum lapping length for reinforcement of $16 \mathrm{~mm}$ in diameter.

Second, studies are required on the F-frame samples by changing the size and thickness of steel plates keeping in mind the end goal to get a practical size of steel plate for the port framework to maintain a strategic distance from wastage.

Third, future work could investigate the topic to find solution to the sudden increase of displacement as soon as the connection is loaded. Conduct studies and find solutions to reinforce the construction joint in order to delay the development of cracks at construction joint.

Lastly, it is recommended to improve the anchorage system by developing and inventing new accessories, which are able to provide similar load resisting mechanisms to the beam-to-beam connection, which can be easily installed on the reinforcement as replacement to the welding system. This will significantly improve the ease of work and reduce the duration of construction. Develop a design guideline for the design of the anchorage system to put into practice in construction industry.

\section{Conclusion}

This study has been completed in two part. In the initial segment, six proposed anchorage systems were tried keeping in mind the end goal to procure their execution and conduct. In the second some portion of this study, the best entertainers of the six proposed anchorage systems were decided for further testing. The best anchorage systems utilizing welding steel end plates that is near the routine lapping framework, was chosen as the beam-to-beam connection in Part two for further study. The followings are a few conclusions that are acquired through the testing of the welded steel end plates connection:

It was found that steel plates can be used to enhance the performance of anchorage system as they have significantly increased the effective areas to resist slipping force between reinforcement bar and concrete.

Other findings showed that welded end plate system can be used to replace the conventional reinforcement bar lapping system although inadequate lapping length is provided. The proposed connection is able to provide comparable loading capacity and undergoes similar loading behavior as compared to the conventional lapping.

The empirical findings of this study showed that once the lapping length increases, the loading capacity, as well as the moment capacity increases. The optimum lapping length is yet to be determined through this research. Therefore, further studies are required.

The study provided the academic community with future work to further research the topic of this study and to enhance the performance of the beam-to-beam connection. Empirical implications for interested party were given and discussed.

\section{References}

[1] British Standard Institution. Structural Use of Concrete BS8110: Part 1: 1997: London, Clause 3.12.8.4

[2] Thompson, J.O.Jirsa, J.E. Breen, R.E. Klingner (2002) "Anchorage Behavior of Headed Reinforcement"

[3] Mohamed and L.A. Clark (1992) "Bond behaviour of low-strength concrete"

[4] Iverson, J. K., and Hawkins, N. M., "Performance of Precast/Prestressed Concrete Building Structures During Northridge Earthquake,” PCI JOURNAL, V. 39, No. 2, March-April 1994. 